\title{
Impact Fees: Practical Guide For Calculation And Implementation
}

\author{
by Dennis H. Ross, Fellow, ASCE, and Scott Ian Thorpe, RCS Principal
}

\begin{abstract}
The use of development impact fees (DIFs) to finance public facilities necessary to accommodate new growth is a concept that has gained acceptance in recent years. California and Florida are considered by many to be the leading areas for the development of theory, practical models, and legislation for determining growth-related costs and calculating impact- fees for new construction. Two methods of calculation of impact fees are discussed: inductive and deductive. A total of 22 potential impact fees for public facilities have been identified, including the conventional water, sewer, and street impact fees. Other potential impact fees include public safety facilities (police and fire), library, public art, and day-care facilities. The consequences of not using impact fees to offset the cost of providing adequate public facilities for new growth are far-reaching. Often the full effects of growth are not felt, or recognized, by the community for many years. The community may simply wake up one day to discover that they need to improve a street or intersection to alleviate congestion.
\end{abstract}

This article was originally presented at the September 9-11, 1991, ASCE Successful Land Management II: Managing and Paying for Growth Conference, held at San Diego, CA, and was printed in the September 1992 issue of the Journal of Urban Planning and Development.

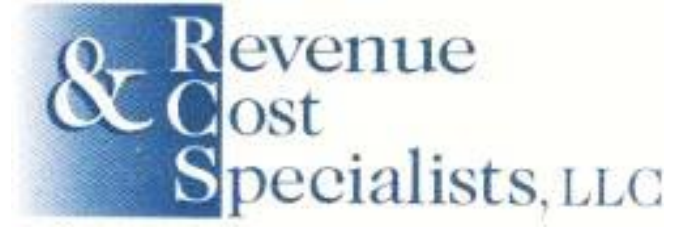

Revenue \& Cost Specialists (RCS) cost@revenuecost.com (714) 992-9020

http://www.revenuecost.com

RCS Principals have been helping public agencies with their financial planning since 1975 


\section{Background and Introduction}

The use of development impact fees (DIFs) to finance public facilities necessary to accommodate new growth is a concept that has gained acceptance in recent years. California and Florida are considered by many to be the leading areas for the development of theory, practical models, and legislation for determining growth-related costs and calculating impact fees for new construction.

In spite of the general acceptance of DIFs, many public officials, developers, and the general populace still do not understand the basis for impact fees. There is a need for a practical discussion of what types of facilities can be financed with impact fees and how to calculate the fees.

Philosophical discussions on the need for impact fees and the effect on the economy of the community may continue indefinitely. However, the rationale for charging impact fees is based on the premise that new development should pay the costs associated with growth. Conversely, the existing residents should only bear the costs of improving existing services.

\section{Historical Perspective}

\section{Impact Fees - Why Now?}

Impact fees are not a new issue; they have been used since the 1920's, as evidenced by the U.S. Department of Commerce's Standard Planning Enabling Act enacted in 1922. (Lurz et al. 1990). Impact fees were first used to manage growth and urban sprawl. Impact fees have also been used for many years in utilities and enterprise funds in the form of connection fees, system development charges, or buy-in fees.

The resurgence of impact fees is caused by several factors working in concert to provide new sources of financing to provide public facilities associated with growth. The revival of impact fees as a form of growth control has also led to increased use of the fees according to Liberty Township, Illinois, supervisor F. T. "Mike" Graham (Lurz 1989).

The taxpayer revolt of the 1970s, led by California's Proposition 13, has been credited with (or been responsible for, depending on your perspective) the increase in fees charged by public agencies. The decline in property taxes available for public projects has resulted in the agencies looking for alternative sources of revenues.

There have also been numerous changes in the profile of capital-project spending over the past years.

Federal spending on capital projects has decreased significantly in the past 10 years. In 1981, the federal government supplied $43 \%$ of the capital for public-works projects. Eight years later, that figure had dropped to $27 \%$ (Lurz et al. 1990), a 37\% reduction in federal spending. 
Changes in technology have contributed to the increased sophistication of public-works projects. With this new sophistication comes added costs that have eroded the financing ability of public agencies.

Changes in environmental costs of public projects have further strained the budgets of public agencies. These costs come in the form of increased regulation, mitigation expenses, and the most elusive cost -- time. The public agency can no longer simply march out in an open field and build a road or sewer line. The mention of environmental costs is neither an endorsement nor criticism of the trend -- the point is that costs have swelled due to increased environmental consciousness.

Increased demands from the citizens living in the community have, without doubt, resulted in the increased cost associated with public projects. Especially in urban areas, narrow roads and thoroughfares without curbs and sidewalks that were acceptable in the 1950s are no longer acceptable in the 1990s. The American population today is more educated, more sophisticated and more likely to express desires (and demands) for better public facilities to elected officials than at any time in the past.

A shift in public policy regarding the responsibility for providing the infrastructure for growth (implying economic growth) has shifted from the community at large to those benefiting from the growth according to Paul Barru, a Denver builder (Lurz et al. 1990).

These points lead to the reality that public projects are more expensive today than they were in the past -- all of this without even starting to consider normal inflation of project costs.

\section{Philosophy of Impact Fees}

The premise on which impact fees are based is that development should pay for the cost of providing the facilities necessary to accommodate growth (Recht 1988). The cost of projects needed to support growth are financed with impact fees based on some measurement of a development's impact on future needs.

Impact fees are not intended to be used for operational expenses or to pay for capital improvements to correct an existing deficiency or shortfall.

\section{Legal Framework}

Several states have passed statewide legislation that affects the ability of public agencies to levy impact fees. The following are some of the most noteworthy.

\section{California.}

AB 1600 (Cortese), which became effective on January 1, 1989, regulates the way that impact fees are imposed on development projects. The agency imposing the fee must (1) Identify the purpose of the fee; (2) identify the use to which the fee is to be put, including 
identifying the public facilities to be financed; (3) show a reasonable relationship (nexus) between the fee's use and the type of development project; (4) show the reasonable relationship between the public facility to be constructed and the type of development; and (5) account for and spend the fees collected only for the purposes and projects specifically used in calculating the fee.

\section{Florida.}

The Growth Management Act of 1985 requires local agencies to maintain adequate service levels for public facilities and prohibits approval of development that would cause a reduction in service level. The act also requires the local government to provide public facilities that are consistent with the community's land-use plan. The act does not specifically allow impact fees, since the courts have ruled that the authority to levy such fees is a function of the Florida Constitution.

\section{Illinois.}

A single-paragraph bill was adopted by the legislature in 1987 that allows collection of transportation impact fees (Lurz 1989). The bill was so written that it affects only two counties (DuPage and Lake), due to their population.

\section{New Jersey.}

The Transportation Development District Act of 1989 allows the creation of transportation improvement districts (TIDs) and transportation development districts (TDDs) (Stepanek 1990). The districts are formed by the New Jersey Department of Transportation on petition of local officials. The legislation provides for the development of a master traffic plan to measure the extent of existing deficiencies and the impact of future development. Impact fees can then be charged to development based on specific impacts and projects necessary to offset the impact.

\section{Texas.}

The state of Texas has been credited with the first legislation specifically allowing cities to impose impact fees (Bogard 1990). The Texas law, unlike other states' legislation, specifies not only the procedure for calculating fees but also the formulas to be used and those improvements that may be financed by impact fees. The law has been dubbed by Robert Burchell of Rutgers University as "prohibition by authorization" (Bogard 1990).

Other states and many local government agencies have adopted legislation affecting impact fees. The examples mentioned are intended only to show that impact fees are not an isolated financing technique but, rather, a nationwide trend. 


\section{Information Needed to Calculate Impact Fees}

Before beginning the impact-fee calculation process, there are information sources that must exist or be generated. The essential data consists of reliable information on what the community will look like in the future (20 or more years) or at theoretical build-out.

The list of projects to be financed with impact fees should be derived from the following information sources:

- General plans or comprehensive plans, including updates.

- Zoning maps.

- Master plans.

- Master facilities plans.

- Capital improvement plans.

Planning statistics on the future population, ultimate land use, undeveloped parcels, and sizes of parcels will be used to determine the amount of growth to be anticipated. Existing land-use and zoning data will provide a basis for evaluating the current situation.

Master facilities plans that address the methods of providing service to future residents will provide the foundation for constructing a capital improvement plan (CIP). The master facility plan should ideally extend to the ultimate build-out condition of the community.

Each project included in the CIP should be clearly identified by a descriptive title or supplemental description. The projects should contain a cost estimate, schedule, and location. An allocation of the relative benefit between existing users and future users should also be prepared for each project.

\section{Rational Nexus Standard}

The utterance nexus has become a frequently used term -- feared in local government circles. The word stems from the Latin word nexum, which refers to a type of formal contract in Roman law. In Roman law, the term nexum expressed the tie or obligation involved in contracts (Black's 1968). The term nexum was also used interchangeably with obligato -- a legal bond obliging performance under the law of the land.

The use of the rational nexus standard, or nexus, has been applied to most laws and cases pertaining to development. Some of the most notable are the Florida Growth Management Act of 1985, the Banberry case in Utah (Banberry Development Corporation v. South Jordan City, P.2d 899, Utah 1981), and the infamous Nolan case in California (Nolan v. California Coastal Commission, 483 U.S. 825, 1987).

The search for the elusive nexus may be the snipe hunt of the 1980s and 1990s. There does not seem to be a clearly defined definition of what constitutes nexus between development (growth) and public facilities (projects). In the cases where impact fees have 
been involved, each court appears to have a slightly differing view of what constitutes nexus.

There may be varying levels of ability to defend the nexus between the need for public facilities and the impact of growth. The more specific an agency is in defining the impact of development in how individual projects will mitigate the effects of growth, the more probable the nexus. While the nexus issue is difficult to define, the rights of developers are not.

\section{Rights of Developers}

The developers, and ultimately the end users, have certain rights regarding the development of impact fees.

Developers have the right to know what they are paying for. Impact fees are a significant portion of the cost of developing both residential (Lurz et al. 1990) and commercial properties. An Orange County, California, survey (Lurz and McLeister 1990) found at least three cities where impact fees can exceed $\$ 20,000$ per dwelling.

A San Francisco Superior Court recently affirmed that city's right to impose $\$ 3,100,000$ in transit-impact development fees on a local developer of an office building (Rauber 1990). The agency imposing the impact fees should be prepared to be specific about the projects for which the fees are to be used.

Developers have the right to equal treatment. One of the comments expressed by developers is the concern that they be treated equally (Hinkelman 1987). In communities without impact fees, developers are often at the mercy of the local agency for off-site improvements to mitigate the impact of development. An important feature of a system of well-defined impact fee charges is the knowledge that all developers, big and small, will be treated equitably. As Atlanta developer Bob Kern said, "If my development is going to put 500 additional cars per day on (an arterial street), then I would be willing to pay a pro rata share with other developers whose projects are going to put 10,000 cars per day on that artery" (Hinkelman 1987). Jack Sorenson, past president of the Home Builders Association of Greater Chicago, said, "Builders are the first to acknowledge the need for proper transportation, sewers, water lines and so forth. What builders want . . . are fees that are fair" (Adams 1989).

Developers have a right to know that the projects for which they have paid impact fees will be built. In the state of California, local agencies are required to maintain suitable fund accounting to assure that impact fees are used for the uses intended. Raymond Brown of BelleMeade Development Corporation in New Jersey said, "Developers can be placated by the knowledge that any fees or services collected will go to benefit their projects and not to be siphoned off to aid some other area or agency" (Stepanek 1990).

Developers have the right to support impact fees. According to Linda Presez, impact fee coordinator for Palm Beach County, Florida, "'Some of the largest developers in Palm 
Beach County are strong supporters of the impact fee because they recognize that it is a way to maintain the quality of life,' and as such enhance the value of their property investment" (Stepanek 1990).

Developers have the right to pay for improvements that will benefit their development. Developers also have the right to expect that their payments will not be diverted to finance improvements not related to growth.

\section{Two Forms of Calculation of Impact Fees -- Inductive and Deductive}

There are two distinct yet equally valid methodologies for calculating impact fees; inductive and deductive.

\section{Inductive Calculation}

This method employs calculation of the impact cost by determining the cost and the capacity of a particular facility and identifying it as the model for all future facilities. What is known is the cost and capacity of a particular facility, what is unknown is the base amount that will require use of the facilities and, thus, the total magnitude of those facilities that will be required.

As an example, according to the National Fire Protection Agency standards, an urban I (highly urbanized area) fire station can meet the needs of a residential population of 15,000 residents; an urban I station can also serve 9,375,000 sq $\mathrm{ft}(870,938 \mathrm{sq} \mathrm{m})$ of commercial/industrial space, or any pro-rata combination of residential and commercial.

The cost and service capacity of the facility is known, but the amount of additional residents and industrial/commercial feet at build-out of the agency are the unknowns. Using this method and assuming land and construction costs to be uniform throughout the state, the impact fee would not vary from jurisdiction to jurisdiction.

\section{Advantages of Inductive Calculation}

The primary advantage of using this type of impact fee is that it is absolute; when $9,375,000 \mathrm{sq} \mathrm{ft}(870,938 \mathrm{sq} \mathrm{m})$ of commercial, industrial, or office space or 15,000 residents (or any combination of the two), are added, there will be adequate monies for one urban I station. However, the typical station may not meet the special needs of the community.

A second advantage of this methodology is that major changes to general plan growth estimates do not affect the calculations. It matters little how much residential, commercial, or industrial properties are constructed. The new development, either residential or commercial, pays its pro- rata share of the need based upon the model. Such a system is, in effect, a no-fault impact-fee determination. 


\section{Disadvantages to Inductive Calculation}

The disadvantages to this method of fee calculation are threefold. First, the fee is based on the service capabilities of a typical model, generally a conservative one, that does not take into consideration unusual or special needs of the community.

The specific needs may affect the cost of the facilities and, thus, the fee. If the fire station's service capabilities differ significantly from that of the model, the fees collected may not match those needed. There may either be too much money collected or, worse yet, not enough fees collected to construct the required station.

Second, such a method focuses on the final product, a fire station or park, but ignores overhead or support facilities such as fire administration offices, park maintenance facilities, and vehicles.

Finally, before construction, the agency must determine how much of the financing for the facility is to be paid from the accumulated impact fees. The remaining fees should come from other resources.

\section{Deductive Calculation}

This method of calculation involves calculating the impact cost by determining the additional demand on a facility or infrastructure from additional population and commercial and industrial square footage. The amount of growth is based upon the agency's general plan and the zoning codes. The specific facilities, identified by a master plan, capital facilities plan, or policy, that are needed as a result of growth are also determined.

The specific facilities, including the cost and any unusual circumstances that determine the need for those specific facilities, are determined. The potential base of undeveloped property is used to distribute the resulting costs. The use of this method explains the difference of fees from one public agency to another public agency. The impact fee calculated by the deductive method is a function of the specifics of geography and the locally defined levels of service.

\section{Need for More Definitive Information}

The deductive method requires a greater level of detail than the inductive method of computation. Deductive calculations require an immense amount of planning for the entire agency, for both developed and undeveloped properties.

As an example, a fire department has an adopted standard of a 5-min response to all fire alarm calls. However, part of the service area may be very hilly and have estate lots of 1 acre $(4,047 \mathrm{sq} \mathrm{m})$ each. Another area might be flatland, with four homes to the net acre. The remaining undeveloped 30 acres $(121,403 \mathrm{sq} \mathrm{m})$ of industrial area could be planned for three munitions factories that require a larger fire station for just that small area. 
To meet the citywide standard of 5-min response to all residential fires the stations built in the hilly portion of the district can only serve approximately 500 homes, although a station in the flatland area can meet the demands of some 2,000 homes.

The proposed munitions factories in the example are special cases and, most likely, would require a response time of less than $5 \mathrm{~min}$. The result is that to supply the appropriate level of service for each residential, commercial, or industrial area the cost will differ for each land use.

\section{Advantages of Deductive Calculation}

The advantage of the deductive calculation of the impact fee is the ability to accommodate the uniqueness of each agency. The service areas are not merely a homogeneous collection of average service areas. The deductive calculation requires proactive planning and estimating and may be subject to frequent updating due to changes in density, land use, and other factors.

\section{Disadvantages of Deductive Calculation}

The disadvantages of this method are several. A considerable amount of effort is required to generate the information necessary for the impact-fee calculations. Inadvertent omissions of projects result in inadequate collection of fees for the facilities.

In addition, deductively calculated fees require more frequent updates. Confusion from the development community may also result from the variance in fee calculation from agency to agency. For large jurisdictions such as a county, it may not be possible to determine the extent or location of growth, thus preventing the use of this method of calculation.

\section{Both Methods Are Valid}

Examples of facilities that lend themselves to inductive calculations are sewage-treatment plants; water-treatment plants; parks; libraries; solid-waste collection; and some portions of police, fire, and other public facilities. Examples of facilities that lend themselves to deductive calculations are streets, sewer collection lines, water distribution lines, street lighting, storm drainage, and fire stations. As in the fire department example, some infrastructure impacts can be calculated using either method. The results may vary considerably from one method to the other.

\section{The Correct Method?}

Is either method more correct? No, since either method would relate the needs and service levels of the community necessary to retain inherent validity. However, the deductive method would result in an impact fee capable of providing facilities specific to the community needs. 


\section{Logical Units of Impact}

Impact that new development imparts on the public infrastructure must be measured for each type of impact fee. The units for these units of impact or factors should be selected carefully to provide a logical unit of measurement that can be defended if challenged.

Logical units of impact for traffic impact fees might be tied to the traffic generation rate. Using a measurement of the square footage of buildings for a traffic impact fee might not be appropriate, unless each type of building had the same level of traffic generation per square foot.

\section{Types of Facilities That Can Be Financed by Impact Fees}

The writers have identified at least 22 categories of facilities that can be financed by impact fees but have not used all of the types listed in practice. They are offered as a potential list for the benefit of the readers.

There is no doubt that creative public officials could devise others, but they would likely be permutations of those presented as follows in no particular order. The writers' preferred units of impact are also included.

- $\quad$ Streets and thoroughfare facilities -- traffic generation rates.

- Traffic control facilities -- traffic generation rates.

- $\quad$ Bridges -- traffic generation rates.

- Storm drainage facilities -- runoff coefficient/impervious area.

- Utility undergrounding -- number of meters/service connections.

- Street lighting -- traffic generation rates.

- Street trees and median landscaping -- traffic generation rates.

- Parks and recreation facilities -- population.

- Other Public facilities (city hall, civic center) -- acreage.

- Law enforcement facilities, equipment, and training -- responses.

- Fire protection facilities, equipment, and training -- incidents.

- Solid-waste collection equipment -- waste generation rates.

- Solid-waste disposal facilities -- waste generation rates.

- Low- and moderate-income housing -- local agency policy.

- Historical preservation and cultural facilities -- population.

- Harbors, ports, and airports -- modal transportation generated.

- Public art, museums, and cultural resources -- population.

- Mass transit facilities and equipment -- traffic generation rates.

- Day-care facilities -- square footage of commercial/industrial.

- Water treatment and distribution facilities -- usage.

- Wastewater collection and treatment facilities -- usage.

- Reclaimed water treatment and distribution facilities -- usage.

- Electric generation and distribution facilities -- usage. 


\section{Indicators of Questionable or Invalid Impact Fees}

Both the inductive and deductive methods of calculating impact fees produce pragmatic, valid impact fees. Many agencies have resorted to devising impact fees that have a questionable relationship to the impact of growth on needed facilities.

Some of the typical fees charged by agencies are briefly described. The following fees should be questioned if they are characterized as impact fees.

\section{Ad-Valorem Fees (Based on Value)}

Any impact fee that is based on the appraised value or estimated construction cost is probably a tax rather than a fee. However, the fees (or tax) may be valid due to state or local legislation. The taxes may also have been grandfathered or adopted prior to limiting legislation.

\section{Front Footage Fees}

Impact fees based on the lineal footage of property bordering on a facility such as a street or sewer line may not be valid. Front footage fees may be valid for reimbursement of previous construction but are not appropriate for impact fees.

\section{Flat Rates}

Uniform, single-value impact fees for all uses (residential and commercial/industrial) would seldom be valid for impact fees.

\section{Illogical Impact Indicator or Factor}

Impact fees that are calculated on a factor that does not make sense are probably invalid. Traffic- signal impact fees based on population or water impact fees based on parcel size (regardless of use) may indicate invalid fees.

\section{Impact-Fee Calculations that Don't Exist}

Some communities simply establish impact fees based on the average or typical fees charged by adjacent communities. Such fees are not based on impact but are solely market-driven decisions that have no relationship to needed facilities.

\section{Financing Operational Costs}

Impact fees collected and simply deposited into the general fund or used for operations are questionable. Impact fees that are not tied to a capital improvement plan or capital projects list or to a master facility plan may not be valid. 


\section{Curing Existing Shortfall or Condition}

Impact fees that are used for projects that deal with correcting existing problems are not valid. That is not to say that a project may not benefit both existing and new residents. In the latter case, impact fees should be used only in direct proportion to the benefits realized by future growth.

\section{Buy-In Fees}

Fees charged on the basis that new residents and businesses will be using the existing infrastructure may not be valid. Buy-in fees have been often compared to country-club initiation fees. A portion of the excess capacity could be considered in calculating impact fees if the agency can show that the existing facilities were oversized to accommodate growth.

\section{Monies Not Used For Stated Purposes}

Impact fees that are collected for one purpose (e.g., traffic signals) should not be used for another purpose (e.g., water treatment and distribution). Monies collected for different types of impact fees should be deposited in separate accounts. When the monies are needed they should be transferred into the appropriate capital account.

\section{Impact-Fee Calculations Must Be Reproducible}

The method of calculating impact fees should be capable of being reconstructed. If the recalculation of the fee cannot reproduce the original fee, the calculation method may be flawed.

\section{Implementation Considerations}

The path to adoption of impact fees is often labyrinthine and strewn with the corpses of well- intentioned public servants. The following discussion is the result of the writers' composite experience in calculation and implementation of impact fees in more than 20 agencies. The following considerations may not be significant factors in successful implementation of impact fees in every community. They are offered in the hope that they will be beneficial to others who travel the impact-fee path.

\section{The realization phase.}

The calculation and adoption of impact fees begins with the acknowledgment of the local agency (either the elected officials or the management staff) that providing public facilities necessary to support development cannot be financed through existing sources of revenue (traditional sources of revenue include property taxes, sales and use taxes, income taxes, business licenses, user charges [usually for utilities], and state or federal grants). Unfortunately in areas of rapid growth, this realization may come too late, but as they say, better late than never. 


\section{The education phase.}

Too many communities launch unsuccessful attempts to implement impact fees. Failure to convey the need for additional revenues to the politicians, residents, developers, and the media is often the reason. Communication is an essential part of the education process, which must include honest, forthright discussions of the financial ability to provide public improvements. It is often not feasible to build capital projects without new sources of revenue.

\section{List of all current deficiencies and future needs.}

It is essential to create an inventory containing the full range of projects needed both now and in the future. Too many agencies become scared when they see the list of all the public improvement projects that must be built to achieve the blueprint envisioned for the community.

The complete list is necessary to show to the developers that they are only paying for future needs. By listing the complete litany of needs, the agency can demonstrate that the impact fees will be used exclusively to support growth induced projects.

Projects that address only current needs are the responsibility of existing residents and should not be financed with impact fees. Projects that serve both existing and future needs should be financed from impact fees and other sources.

Be cautious when attempting to finance facilities that are not currently provided with impact fees. If future needs include facilities that are not provided in the community (e.g., a civic theater where none exists today), it may be difficult to establish a need and corresponding nexus.

\section{Special-interest groups.}

Developers and special-interest groups should be included in the process early. There is nothing worse than having a major special-interest group show up at the public hearing saying that they did not have any notice or input into the development of the impact fees. The surfacing of any group that claims that they did not receive adequate notice will almost certainly result in a continuance of the hearing. Some of the potential specialinterest groups include:

- Individual builders or developers.

- Builder/developer associations.

- Realtors.

- Environmental groups.

- Anti-growth groups.

- Chamber of commerce.

\footnotetext{
•
} 


\section{Planning commission involvement.}

Amazing as it may seem, the planning commission is seldom directly involved in the impact-fee setting process. The writers have no explanation for this phenomenon, nor are they willing to make any judgment about the merits of this practice.

\section{Environmental clearances.}

While the setting of fees for services provided by a public agency are usually exempt from environmental regulation, the adoption of impact fees may require environmental clearance. The precursors to impact-fee setting, general or comprehensive plans, and use of the fees for capital projects are subject to environmental regulation. The writers have not found any court cases that would support the notion that the impact-fee setting process requires environmental clearances. In the lack of conclusive evidence, agencies should review the environmental requirements. The agency should make appropriate findings as part of the fee setting process.

\section{Formal meetings.}

Public hearings are normally held as part of the adoption of new fees or charges. In California, not only is a public hearing required but the basis for calculation of the fees must also be available for public inspection before the hearing. As a matter of public accountability, it would not be prudent for an agency to try to circumvent the public hearing process.

\section{Legislation.}

The format of ordinances or resolutions used to adopt impact fees vary according to the statutory requirements of the state and local agency. The largest variation may occur not due to any statute but as a function of the agency's legal counsel. One agency in the state of California adopted a separate ordinance for each impact fee on the advice of counsel that the invalidation of one fee could affect the others. The key to the ordinance or resolution is to establish the nexus for the fee within the document, or by reference to a specific study or report.

\section{Accountability.}

Once the impact fees have been implemented, there is a need to provide accurate accounting or tracking of the fees collected and the use of those fees. California's AB 1600 requires fees to be expended, or committed, within five years of their collection. Since the law is barely two years old, no one can predict how the courts will react to challenges about violation of the five year limit. Even without a statutory requirement to expend the impact fees on growth- related projects, it would be prudent to be able to show developers that their money was spent on growth-related projects. 


\section{Recommendations for Success}

Don't use impact fees as a method of growth control. Use the impact fees to contribute the financing to provide the public facilities necessary to accommodate the growth in the community. The impact fees should merely accommodate the growth envisioned in the community's general or comprehensive plan. If that growth is inappropriate, change the plan.

Determine capital improvement needs through build-out. It is essential to have complete information on capital needs. Many communities do not have a practical capital improvement plan that addresses the public facility needs for even the next five years. Impact fees based on incomplete CIPs will not generate sufficient revenues to assure that development pays its own way.

Show all capital improvement needs, including those not being financed with impact fees. The identification of projects necessary to overcome existing deficiencies is needed to show the development community that they are not being asked to correct existing problems. A corollary is that the community must demonstrate that they are using impact fees exclusively for growth-related projects. Other sources of revenue must be found for projects benefiting existing residents.

Develop long-range financing strategies for projects not financed with impact fees. Projects that are not financed with impact fees will need to have other sources of revenue for construction. The agency should try to identify potential sources of revenue that will be used to build nongrowth projects. The extent that the agency is successful in identifying specific sources of revenue may be an indicator to the reality of achieving the ultimate goals of the community's general or comprehensive plan.

Do not attempt to finance operations or current deficiencies with impact fees. Impact fees justified by the need to offset the effects of growth should not be used for operating expenses. To do otherwise would be unethical and could result in a loss of faith by the community.

Produce a comprehensive impact-fee report, including rationale and calculations, make the report readily available to the public. Performing an extensive study prepares the agency to answer questions about the way the fees were calculated and the use to which the fees will be put. Complete documentation can be a powerful form of defense against challenges to the agency's ability to impose impact fees.

Use the deductive method of calculating impact fees where possible. The deductive method requires detailed information about the actual facilities necessary to serve the community at theoretical build-out. The level of detail that is needed takes a concerted effort by the agency to project facility needs. By using the deductive method to calculate impact fees, an agency can be reasonably sure of providing equity, nexus, and sufficient fees to support needed capital projects. If the information is not available for the deductive calculations, then use the inductive method. 
Update the impact fees periodically. Impact-fee calculations should be updated often to ensure that the assumptions are still valid. The projected growth of the community, the facility needs, and the cost for providing those facilities should be verified. Reviewing the impact-fee calculations together with the capital improvement plan or budget would be ideal. At a minimum, the impact fees should be reviewed every two years, or whenever a major change occurs (e.g., major annexation or general plan revision) in the community.

\section{References}

Adams, E. (1989). "Learn to live with infrastructure costs." Professional Builder, 54(16), 32.

Black's Law Dictionary. (1968). Revised 4th Ed., West Publishing Co., St. Paul, Minn.

Bogard, A. (1990). "Impact fees in a small Texas city." Government Finance Rev., 5(3), 15.

Brown, G. M. (1988). "Impact fees: Private financing of public facilities." Pennsylvanian, $27(12), 8$.

Hinkelman, M. (1987). "Good, reasonable extortion." Business Atlanta, June, 86.

Lurz, W. H. (1989). 'The politics of anti-growth hit the Midwest: In the Chicago suburbs, builders face anti-growth measures in two counties -- and the Implications may be national." Prof. Builder, 54(2), 26.

Lurz, W., Brady, S., Heinly, D. (1990). "Let America build." Prof. Builder and Remodeler, 55(17), 88.

Lurz, W., and McLeister, D. (1990). "Infrastructure: Who should pay?" Prof. Builder, $55(7), 112$.

Rauber, C. (1990). "Levi Plaza owner must pay transit fee." San Francisco Business Times, 5(11), Nov. 9, 8 .

Recht, J. R. (1988). "Rose bushes have thorns." Devel. Impact Fees, A. C. Nelson ed., Planners Press, Chicago, Ill., 380.

Stepanek, S. (1990). "Paving the road for development: Heightened regulation ties projects to infrastructure improvements." Buildings, 84(9), 118. 